\title{
Neuronal Transgene Expression in Dominant-Negative SNARE Mice
}

\author{
Takumi Fujita, ${ }^{\star}$ Michael J. Chen, ${ }^{\star}$ Baoman Li, Nathan A. Smith, Weiguo Peng, Wei Sun, Michael J. Toner, \\ Benjamin T. Kress, 난 \\ Center for Translational Neuromedicine, University of Rochester Medical School, Rochester, New York 14642
}

Experimental advances in the study of neuroglia signaling have been greatly accelerated by the generation of transgenic mouse models. In particular, an elegant manipulation that interferes with astrocyte vesicular release of gliotransmitters via overexpression of a dominant-negative domain of vesicular SNARE (dnSNARE) has led to documented astrocytic involvement in processes that were traditionally considered strictly neuronal, including the sleep-wake cycle, LTP, cognition, cortical slow waves, depression, and pain. A key premise leading to these conclusions was that expression of the dnSNARE was specific to astrocytes. Inconsistent with this premise, we report here widespread expression of the $A n S N A R E$ transgene in cortical neurons. We further demonstrate that the activity of cortical neurons is reversibly suppressed in dnSNARE mice. These findings highlight the need for independent validation of astrocytic functions identified in dnSNARE mice and thus question critical evidence that astrocytes contribute to neurotransmission through SNAREdependent vesicular release of gliotransmitters.

Key words: adenosine; EEG; GFAP; sleep; SNARE

\section{Introduction}

A series of studies spanning the past decade has revealed that astrocytes participate in complex neural functions by actively modulating neuronal networks in an activity-dependent manner. Although nonelectrically excitable, a key feature of astrocytes is their ability to exhibit a form of excitation defined by transient increases in cytosolic calcium ions, which in turn initiates a cascade of signaling pathways thought to confer bidirectional feedback to synaptic transmission (Barres, 2008; Gourine and Kasparov, 2011). A prevailing hypothesis is that astrocytes exert control of neural networks via the exocytic release of gliotransmitters (Agulhon et al., 2008; Araque et al., 2014; Volterra et al., 2014); however, evidence in support of this model remains inconclusive (Agulhon et al., 2008; Nedergaard and Verkhratsky, 2012; Sun et al., 2013).

An important step leading to many of the rapid advances in the field of neuroglia signaling was the generation of transgenic dominant-negative domain of vesicular SNARE (dnSNARE) mice, which were engineered to target astrocytic exocytosis by

\footnotetext{
Received June 24, 2014; revised 0ct. 12, 2014; accepted 0ct. 21, 2014.

Author contributions: T.F., M.J.C., N.A.S., A.B., T.T., and S.W. designed research; T.F., M.J.C., B.L., W.P., W.S., M.J.T., B.T.K., L.W., and T.T. performed research; T.F. and M.J.C. analyzed data; T.F., B.T.K., and M.N. wrote the paper. This work was supported by the National Institutes of Health (Grants R01DE022743, R01NS075177, and R01AT007945). The content is solely the responsibility of the authors and does not necessarily represent the official views of the National Institutes of Health. We thank Ken McCarthy for generously sharing transgenic mice and Maosheng Xia and Clifford Pierre for expert technical help.

The authors declare no competing financial interests.

*T.F. and M.J.C. contributed equally to this work.

Correspondence should be addressed to either Maiken Nedergaard, MD, PhD, or Takuma Fujita, PhD, Center for Translational Neuromedicine, University of Rochester Medical School, 601 Elmwood Ave., Box 645, Rochester, NY 14642.E-mail: nedergaard@urmc.rochester.edu or Takumi_Fujita@urmc.rochester.edu.

DOI:10.1523/JNEUROSCI.2585-14.2014

Copyright $\odot 2014$ the authors $\quad 0270-6474 / 14 / 3416594-11 \$ 15.00 / 0$
}

expression of a dominant-negative domain (cytosolic portion) of vesicular SNARE protein VAMP2 (vesicle-associated membrane protein 2)/synaptobrevin2 (Pascual et al., 2005). In these mice, formation of the SNARE complex between vesicles and the plasma membrane is inhibited by the redundant expression of dnSNARE, which competes with endogenous VAMP2 (Zhang et al., 2004). To achieve inducible and reversible temporal regulation of dnSNARE transgene expression, dnSNARE mice use the "Tet-Off" system, in which treatment with tetracycline or its analog doxycycline (Dox) turns gene expression "Off." Selectivity to astrocytes was obtained by driving transgene expression by the glial-fibrillary acidic protein (GFAP) promoter (Brenner et al., 1994).

This transgenic mouse enabled studies showing that astrocytes control the threshold for induction of LTP in hippocampal slices (Pascual et al., 2005; Halassa et al., 2010). Behavioral analysis of dnSNARE mice has further documented that astrocytes play a critical role in sleep pressure accumulation and the cognitive consequences of sleep loss (Halassa et al., 2009b; Hines et al., 2013). Additional studies showed that inhibition of a SNAREdependent pathway in astrocytes protects against damage after stroke (Hines and Haydon, 2013) and modulates baseline mechanical nociception (Foley et al., 2011) as well as progressive development of temporal lobe epilepsy (Clasadonte et al., 2013). This body of work has identified adenosine as the principle gliotransmitter by which astrocytes exert control of neural networks (Fellin et al., 2009). However, these studies did not evaluate how inhibition of the SNARE complex in astrocytes affects the extracellular concentration of adenosine in vivo. Crucially, all of these observations depend on the premise that the specificity of the dnSNARE manipulation is limited to astrocytes. Expression of dnSNARE in neurons could have major impact on neural net- 
work activity because glutamatergic transmission critically depends upon the formation of the SNARE complex between synaptic vesicles and the presynaptic membrane (Tafoya et al., 2006). Earlier work has shown that deletion of endogenous VAMP2 reduces fast $\mathrm{Ca}^{2+}$-triggered synaptic fusion events by $>100$-fold and is incompatible with survival (Schoch et al., 2001), suggesting that even a minor disruption of neuronal vesicular release has the potential to suppress glutamatergic transmission.

In the present study, we assessed the cellular specificity of the dnSNARE transgene expression in dnSNARE mice. Our analysis showed that cortical neurons in this mouse model express the dnSNARE transgene, demonstrating for the first time that transgenic mice using inducible GFAP promoters can induce transgene expression in adult neurons. This observation extends prior reports documenting that transgenes controlled by the constitutive GFAP promoter can be found in neurons in nonconditional transgenic mice (Zhuo et al., 2001; Su et al., 2004).

\section{Materials and Methods}

Animals, EEG collection, and microdialysis. Conditional reversible expression of dnSNARE, a dominant-negative domain of vesicular SNARE VAMP2/Synaptobrevin2 under the control of GFAP promoter was generated by crossing two transgenic lines: GFAP-tTA mice, which expresses the tetracycline transactivator under the control of GFAP promoter, and tetO-dnSNARE mice, which express three transgenes separately under the control of a tetO promoter: (1) dnSNARE, (2) EGFP, and (3) LacZ. Both transgenic mice lines were kindly shared by Dr. Ken McCarthy, University of North Carolina, Chapel Hill, NC (Pascual et al., 2005). To prevent the developmental expression of dnSNARE, the mice were bred in the presence of Dox (Sigma-Aldrich) in drinking water $(100 \mu \mathrm{g} / \mathrm{ml})$. Amber bottles were used to prevent light exposure. Three- to six-monthold double-positive mice for both GFAP-tTA and tetO-dnSNARE genes (dnSNARE mice) of either sex were used.

Surgical implantation of EEG electrodes over parietal cortex and the microdialysis guide cannula were performed under anesthesia (100 $\mathrm{mg} / \mathrm{kg}$ ketamine, $10 \mathrm{mg} / \mathrm{kg}$ xylazine, i.p.) and aseptic conditions as described previously (Tian et al., 2005; Oberheim et al., 2008). Custom platinum EEG electrodes ( 0.003 inch diameter; Plastics One) were inserted epidurally (1.5-2.0 mm posterior to bregma, $1.0-3.0 \mathrm{~mm}$ lateral to midline). The lead sockets were attached to the screws and inserted in a three-hold plastic pedestal (MS333; Plastics One). A total of three leads were used, one for each hemisphere and one as a grounding electrode. Microdialysis probe tip (hippocampus, $2 \mathrm{~mm}$; basal forebrain, $1 \mathrm{~mm}$ membrane length, $\mathrm{BASi}$ ) was positioned at the following coordinates: hippocampus: anterior-posterior: $-3.0 \mathrm{~mm}$; medial-lateral: $+2.9 \mathrm{~mm}$; dorsal-ventral: $-3.1 \mathrm{~mm}$ from brain surface: basal forebrain: anteriorposterior: $+0.1 \mathrm{~mm}$; medial-lateral: $+1.2 \mathrm{~mm}$; dorsal-ventral: $-5.5 \mathrm{~mm}$ from brain surface. The probe was equilibrated with artificial CSF containing the following (in mM): $150 \mathrm{NaCl}, 4 \mathrm{KCl}, 1 \mathrm{CaCl}_{2}, 1 \mathrm{MgCl}_{2}, 1.25$ $\mathrm{NaH}_{2} \mathrm{PO}_{4}, 15 \mathrm{HEPES}, \mathrm{pH} 7.4$, flow rate at $0.075 \mu \mathrm{l} / \mathrm{min}$ for $24 \mathrm{~h}$ to obtain stable baseline of adenosine concentrations. All EEG recordings and microdialysates were collected in a room with a normal light-dark cycle (12/12, lights on at 6:00 A.M.) for up to $48 \mathrm{~h}$ after the postsurgery recovery period/habituation of $3 \mathrm{~d}$. EEG was recorded using a low- and highpass filter of 0.3 and $100 \mathrm{~Hz}$. Before each recording set, animals were given a 2 week period reversal of On-/Off-Dox. Animals underwent a total of 4 recording sets of $48 \mathrm{~h}$ with a 2 week rest period and exposure to the reverse condition (On-/Off-Dox) maximally. Power spectrum analysis of EEG data were collected using both Axoscope and Neuroscore (Wisor and Clegern, 2011; Wisor et al., 2011). Using Clampfit, $6 \mathrm{~h}$ averaged spectra from artifact-free epochs were analyzed and broken down into delta $(0-4 \mathrm{~Hz})$, theta $(4-8 \mathrm{~Hz})$, alpha $(8-13 \mathrm{~Hz})$, and beta $(13-20$ $\mathrm{Hz}$ ). In addition, Neuroscore (DSI) allowed for accurate confirmation of delta wave activity. Total power was compared among all groups and an averaged power was obtained. Using a custom-made chamber that mimics gentle handling (Schmidt and Wisor, 2012), mice are subjected to sleep deprivation by a slowly rotating lever arm that prevents the animal from sleeping (Wisor et al., 2011). The lever moved at a slow enough pace (5-6 rotations per minute) to minimize stress in the animals while fast enough to prevent sleep. Animals were sleep deprived for $6 \mathrm{~h}$ from 6:00 A.M. to noon and allowed sleep recovery from noon to 6:00 P.M. All animal procedures followed National Institutes of Health guidelines and were approved by the Institutional Animal Care and Use Committee of the University of Rochester.

Adenosine measurement. High-performance liquid chromatography (HPLC) analysis of purines in microdialysis samples was performed using CoulArray 5600A HPLC system (ESA) and a model 526 UV detector (ESA) as described previously (Goldman et al., 2010; Fujita et al., 2012; Takano et al., 2012). Chromatographic separation was achieved using a Lichrospher $100 \mathrm{RP}-18 \mathrm{e}$ column ( $5 \mu \mathrm{m}, 250 \mathrm{~mm} \times 4 \mathrm{~mm}$; Merck). For measurements of samples, we used the mobile phase, which consisted of $215 \mathrm{~mm} \mathrm{KH}_{2} \mathrm{PO}_{4}, 0.6 \mathrm{~mm}$ tetrabutylammonium bisulfate, $4.5 \%(\mathrm{v} / \mathrm{v})$ acetonitrile (HPLC grade), and HPLC grade water, $\mathrm{pH}$ 6.8. The flow rate was maintained at $0.35 \mathrm{ml} / \mathrm{min}$. Daily calibration curves were prepared by a four points standard $(1,0.5,0.1$, and $0.05 \mu \mathrm{M})$ of adenosine in $0.4 \mathrm{M}$ perchloric acid, respectively. Eluted purines were detected at $254 \mathrm{~nm}$ and the chromatographic peaks were integrated using CoulArray software.

Histology. The mice were deeply anesthetized with a mixture of ketamine/xylazine and perfused intracardially with ice-cold PBS followed by freshly prepared $4 \%$ paraformaldehyde in $0.1 \mathrm{M} \mathrm{PB}, \mathrm{pH}$ 7.4. The brains were removed and immersed in the same fixative solution for $1 \mathrm{~h}$. After cryoprotection in a series of $10 \%, 20 \%$, and $30 \%$ sucrose, the tissues were frozen in methylbutane precooled in dry ice and stored at $-80^{\circ}$ (Nedergaard et al., 2002). Twenty-micrometer-thick sagittal cryosections were prepared and labeled with chicken anti-Map2 (1:400; Abcam), mouse anti-VAMP2 (1:100; Synaptic Systems), or rabbit anti-NeuN (1:200; Millipore) antibodies. Secondary antibodies were DyLight 594- and 649tagged goat or donkey secondary antibodies (each 1:400; Jackson ImmunoResearch). $\beta$-Galactosidase activity was detected using in situ $\beta$-galactosidase staining kit following the manufacturer's instructions (Agilent Technologies).

Transgenic mice expressing Rol under the control of GFAP promoter were generated by crossing the GFAP-tTA mouse line and the tetO-Rol mouse line (Sweger et al., 2007). To examine Ro1 expression, brain sections from Rol mice under Off-Dox condition were probed with antiFLAG (the epitope tag fused to Ro1) antibody.

Cell culture and immunocytochemistry. Primary neocortical astrocyte cultures were prepared from P0-P2 C57BL/6 pups (The Jackson Laboratory) as described previously (Lin et al., 1998). The dissociated cells were plated on culture flasks and maintained in DMEM/F12 containing $10 \% \mathrm{FBS}, 100 \mathrm{IU} / \mathrm{ml}$ penicillin, and $100 \mu \mathrm{g} / \mathrm{ml}$ streptomycin $\left(5 \% \mathrm{CO}_{2} /\right.$ $95 \%$ air, $37^{\circ} \mathrm{C}$ ). The cells were subcultured on coverslips in 24 well plates for $5 \mathrm{~d}$ and fixed with $4 \%$ paraformaldehyde. Primary neocortical neurons were prepared from $\mathrm{P} 0-\mathrm{P} 2$ C57BL/6 pups (The Jackson Laboratory) as previously reported by Brewer and Torricelli (2007). The dissociated cells were plated on poly-D-lysine-coated coverslips in 24 well plates and maintained in NeurobasalA/B27 medium supplemented with $0.5 \mathrm{~mm}$ Glutamax, $5 \mathrm{ng} / \mathrm{ml}$ mouse FGF2, $0.1 \%$ bovine serum albumin, and $10 \mu \mathrm{g} / \mathrm{ml}$ gentamycin for $8 \mathrm{~d}\left(5 \% \mathrm{CO}_{2} / 95 \%\right.$ air, $\left.37^{\circ} \mathrm{C}\right)$.

For immunocytochemistry, cultured astrocytes or neurons were fixed with $4 \%$ paraformaldehyde in $0.1 \mathrm{M} \mathrm{PB}, \mathrm{pH} 7.4$, for $10 \mathrm{~min}$ and washed in PBS. The fixed cells were blocked with $10 \%$ normal goat serum and permeabilized with $0.1 \%$ saponin. The following primary antibodies were used: rabbit anti-GFAP (1:300; DAKO), mouse anti-Vamp2 (1:200; Synaptic Systems), chicken anti-Map2 (1:500; Abcam). Secondary antibodies were DyLight 488-, 594-, and 649-tagged goat or donkey secondary antibodies (each 1:400; Jackson ImmunoResearch).

Dissociation of brain tissue followed by FACS and immunocytochemistry. Dissociation of mouse cortical tissue was performed as described previously (Brewer and Torricelli, 2007) with minor modifications. Eightday-old C57BL/6 or dnSNARE mice under Off-Dox condition for $5 \mathrm{~d}$ were anesthetized with $100 \mathrm{mg} / \mathrm{kg}$ ketamine and $10 \mathrm{mg} / \mathrm{kg}$ xylazine intraperitoneally and perfused with ice-cold Hanks buffer. The brain was immediately removed and the dissected cortex was cut into small pieces, which were digested with $5 \mathrm{U} / \mathrm{ml}$ papain in $\mathrm{Ca}^{2+}$-free HibernateA con- 
taining $0.5 \mathrm{~mm}$ Glutamax for $30 \mathrm{~min}$ in a water bath at $30^{\circ} \mathrm{C}$. After transferring the tissue to HibernateA containing B27 and Glutamax (HABG), the tissue was carefully triturated and centrifuged over an OptiPrep density gradient. Neurons were enriched and separated from myelin debris using a density gradient of OptiPrep as described previously (Brewer and Torricelli, 2007) before FACS. After centrifugation of the cell suspension with the gradient, Fraction 2 (neurons and other cells) and Fraction 3 (neurons) were used to maximize the yield of neurons. After washing with HABG, cells were collected in NeurobasalA/B27 media, which is supplemented with $0.5 \mathrm{~mm}$ Glutamax, $10 \mu \mathrm{g} / \mathrm{ml}$ gentamycin, and $5 \mathrm{ng} / \mathrm{ml}$ mouse $\mathrm{FGFb}$, and labeled with mouse antipolysialylated-neural cell adhesion molecule (PSA-NCAM, 1:100; Millipore) or mouse IgM control followed by labeling with secondary goat anti-mouse allophycocyanin (APC, 1:200; Jackson ImmunoResearch). Cells were resuspended in cold NeurobasalA/B27 media containing 4',6-diamidino-2-phenylindole (DAPI, 5-10 $\mu \mathrm{M}$ ) to discriminate dead cells.

Cells were sorted using FACS as described previously (Sun et al., 2013). APC was excited by a $633 \mathrm{~nm}$ laser and emissions were collected by a $660 / 20 \mathrm{~nm}$ bandpass filter. DAPI was excited by a $407 \mathrm{~nm}$ laser and emissions were collected by a $450 / 40$ bandpass filter. Single cells were discriminated using pulse width and height measurements and dead cells were excluded based on positive DAPI signal. PSA-NCAM ${ }^{+}$and PSA$\mathrm{NCAM}^{-}$cells were sorted into cold NeurobasalA/B27 media. For examination of sorted cell pools by immunocytochemistry and cell counting, FACS-isolated cells were plated in poly-D-lysine-coated 8-well chamber and fixed with $4 \%$ paraformaldehyde as soon as adherent ( $\sim 10-20 \mathrm{~min})$. The cells were labeled with mouse anti-NeuN (1:500; Millipore) and rabbit anti-AQP4 (1:500; Millipore), followed by labeling with secondary antibodies. For quantitative analysis of purity in PSA-NCAM ${ }^{+}$population, number of cells labeled with Aqp4 in the images (field of view $1272.8 \times 1272.8 \mu \mathrm{m}, 1.24 \mu \mathrm{m} / \mathrm{pixel}$ ) was counted using the ITCN plugin (Center for Bio-image Informatics at UC Santa Barbara) with ImageJ software with the parameters: width of 6 pixels, minimum distance of 18 pixels, and threshold of 3 . Number of DAPI signals in the same images was counted with the parameters: width of 5 pixels, minimum distance of 8 pixels, and threshold of 2.5 and used as a total cell number to calculate the averaged percentage of astrocytes in the population $(n=4$ field of view).

Adult cortical neurons were isolated from 2- to 5-month-old dnSNARE mice under On-Dox or Off-Dox condition (2 weeks after removal of Dox) using the density gradient of OptiPrep, similar to collections of young cortical neurons described above. Although the majority of myelin and cellular debris can be eliminated by removal of the top $6 \mathrm{ml}$ after centrifugation, Fraction 2 also contains some cellular debris. Therefore, only Fraction 3 was collected, resulting in high enrichment of neurons and shortening the sorting time. The dissociated cells were labeled with mouse anti-Neural cell adhesion molecule-1 APC (1: 50; R\&D Systems) or Rat IgG2A APC control (1:50; R\&D Systems). Cells resuspended in cold NeurobasalA/B27 media containing DAPI were sorted as described above.

RNA processing and quantitative PCR. After FACS, total RNA was immediately extracted from cells using either the RNeasy Micro kit or RNeasy Mini kit (Qiagen). Cortical tissue samples were collected from dnSNARE Off-Dox, On-Dox, GFAP-tTA-negative, and C57BL/6J wildtype mice and were prepared using TRIzol RNA isolation method (Life Technologies) with the RNeasy Micro kit for purification. RNA quantity was assessed using the NanoDrop-1000, and RNA integrity was assessed using the 2100-Bioanalyzer. Total RNA was reverse transcribed using Ovation Pico/PicoSL WTA System V2 (NuGEN). Relative quantity of transcripts was assessed using SYBR Green Dye-Based Gene Expression Assays or TaqMan Gene Expression Assays and the 7000 Sequence Detection System. The expression of $d n S N A R E$ transgene was detected with primers encoding a product spanning the rattus norvegicus Vamp2-Mus musculus transthyretin junction to distinguish dnSNARE transgene from endogenous Vamp2 gene (forward 5'-CAAGCGCAAATACTGGTGGAAAA- $3^{\prime}$ and reverse primer $5^{\prime}$-ACTTTGACCATCAGAGGACATT$3^{\prime}$ ). The expression of tTA gene was detected with primers (forward $5^{\prime}$-CAAGAGCATCAAGTCGCTA- ${ }^{\prime}$ and reverse primer $5^{\prime}$-CTCTG-
CACCTTGGTGATC-3') and FAM-labeled probe (5'-CACCTACTACTGATAGTATGCCG-3'; Barton et al., 2002). 18S RNA served as an internal control that all samples were normalized to before calculating relative expression.

\section{Results}

Removal of Dox reversibly suppresses cortical EEG signal in dnSNARE mice

In the "Tet-Off" tetracycline-controlled transcriptional activation system, the tetracycline transactivator (tTA) protein binds to the tetracycline operator (tetO) and drives expression of downstream genes in the absence of Dox (Off-Dox, turning on gene expression, Fig. 1A). In dnSNARE transgenic mice, the GFAP promoter controls the expression of tTA, whereas tetO drives expression of dnSNARE. Vesicular fusion is therefore inhibited in GFAP-expressing cells under the Off-Dox condition, but inhibition of vesicular fusion by dnSNARE can be blocked reversibly by administration of Dox (On-Dox, turning off gene expression, Fig. 1A). Dox was administered before gestation and during rearing of dnSNARE mice to prevent transcription of dnSNARE during development (Pascual et al., 2005). We first assessed the effect of dnSNARE expression on cortical neural activity. Epidural EEG electrodes were implanted over the right parietal cortex in adult dnSNARE mice.

A sharp reduction in EEG power was noted 2 weeks after discontinuing Dox treatment (Off-Dox). Dox was next administered for 2 weeks and a second EEG recording was obtained (On-Dox), resulting in recovery of EEG power. Continuing alternation between On-Dox and Off-Dox conditions consistently reversed the EEG power (Fig. $1 B, C$ ).

\section{Neuronal expression of $d n S N A R E$ and 2 reporter transgenes in dnSNARE mice}

The striking suppression of EEG power in the Off-Dox condition may reflect dnSNARE expression in neuronal populations and direct interference with vesicle-mediated synaptic transmission or alternatively, indirect modulation via gliotransmission. We therefore tested whether the "Tet-Off" system under the control of GFAP promoter drives dnSNARE expression in neurons in dnSNARE mice. Assessment of the specificity of dnSNARE expression was accomplished by neuronal harvesting using a density gradient-based dissociation method (Brewer and Torricelli, 2007) and FACS (Fig. 2A). Cortical tissue was harvested from dnSNARE or C57BL/6 mice pups and the dissociated cells were tagged with an antibody against PSA-NCAM (Seki, 2002; Gomez-Climent et al., 2011; Barker et al., 2012). Two distinct populations of cells, PSA-NCAM ${ }^{+}$(neurons) and PSA-NCAM (other cell types), were isolated. The relative enrichment of neuronal markers in $\mathrm{PSA}^{-\mathrm{NCAM}^{+}}$population was evaluated by both quantitative real-time fluorescence PCR (qPCR) and immunostaining (Fig. $2 B, C$ ). Astrocyte cell number, which was quantified based on Aqp ${ }^{+}{ }^{+}$staining, was $1.31 \pm 0.29 \%(n=4)$ in the PSA-NCAM ${ }^{+}$population. In dnSNARE transgenic mice, the GFAP promoter controls the expression of two reporters ( $\mathrm{LaCZ}$ and EGFP) as well as dnSNARE (Fig. 2A). Surprisingly, PSA$\mathrm{NCAM}^{+}$cells showed expression of dnSNARE, LacZ and EGFP transgenes. Therefore, expression of the $d n S N A R E$ transgene is not restricted to astrocytes but includes neuronal populations. Similar pools of cells harvested from wild-type C57BL/6 (WT) mice exhibited no expression of $d n S N A R E$, LacZ and EGFP transgenes in either PSA-NCAM ${ }^{+}$or PSA-NCAM ${ }^{-}$populations (Fig. $2 D$ ). Expression of $t T A$ gene was observed in both neuronal and glial populations in dnSNARE mice, whereas WT showed no expression (Fig. 2E). 
A

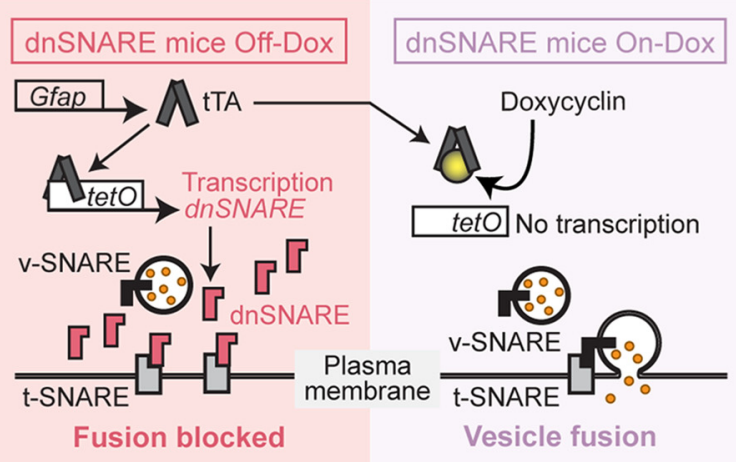

B

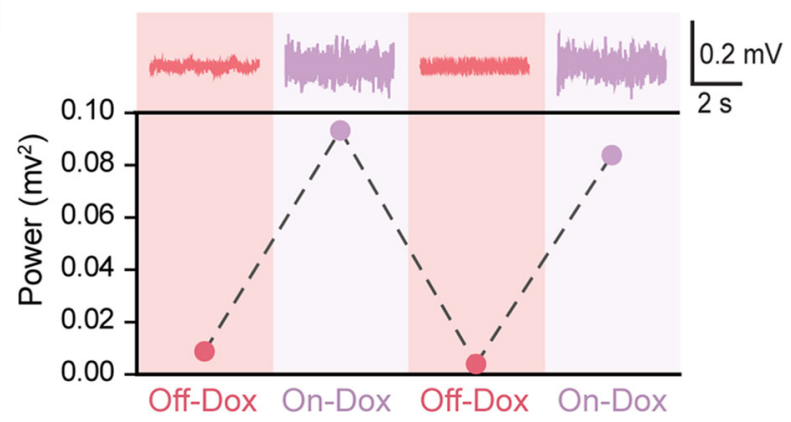

C

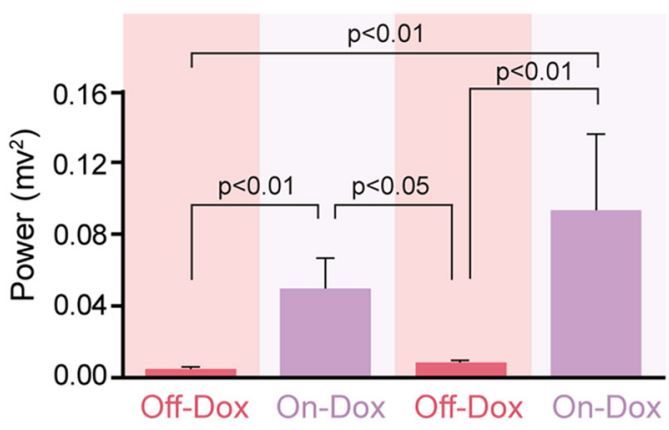

Figure 1. Induction of dnSNARE by removal of doxycycline suppresses cortical EEG power reversibly in dnSNARE mice. A, Schematic outlining the tTA system used in dnSNARE mice. Dox administration via drinking water prevents transcription activation. Removal of Dox induces redundant expression of dnSNARE, which is a cytosolic portion (lacking transmembrane region) of vesicular SNARE (v-SNARE) and thus formation of the SNARE complex between vesicles expressing v-SNARE and the plasma membrane expressing target SNARE (t-SNARE) is inhibited. DnSNARE mice that are positive for both transactivator (GFAP-tTA) and tet operators (tet0dnSNARE) were treated with (On-Dox) or without (Off-Dox) Dox for 2 weeks before each EEG collection. $\boldsymbol{B}$, Top, Representative EEG trace collected from a dnSNARE mouse under On-Dox or Off-Dox condition. Bottom, Representative EEG power showing a reversible decrease in EEG power during Off-Dox periods in dnSNARE mouse. C, Quantification of EEG power in dnSNARE mice under On-Dox or Off-Dox condition. DnSNARE mice during On-Dox periods showed significantly higher EEG power compared with those during Off-Dox periods. One-way ANOVA with post hoc Tukey-Kramer test ( $n=4$, first Off-Dox; $n=5$, first On-Dox and second Off-Dox; $n=$ 3 , second On-Dox). Error bars indicate SEM.

It is generally acknowledged that GFAP expression and its promoter activity is comparatively low in astrocytes located in cerebral cortex unlike spinal cord (Palfreyman et al., 1979; Jany et al., 2013), so it is unclear whether GFAP promoter activity is sufficient to induce $d n S N A R E$ transgene expression in adult cerebral cortex. Therefore, we next collected cortices from adult dnSNARE mice in either the On-Dox or Off-Dox condition and compared the expression levels of $d n S N A R E$ transgene. Compared with the On-Dox group, the Off-Dox group showed higher dnSNARE expression (Fig. 2F). Expression of both LacZ and
EGFP genes were higher in the Off-Dox group than those in the On-Dox group. To further define whether neurons express $d n$ SNARE transgene, cortical neurons were isolated from adult dnSNARE mice under On-Dox or Off-Dox conditions. Enrichment of neuronal marker gene relative to tissue was confirmed by $\mathrm{qPCR}$ analysis (Fig. 2G). Importantly, neuronal expression of $d n S N A R E$ transgene was also observed in adult dnSNARE mice and $d n S N A R E$ expression was higher in Off-Dox neurons than that in On-Dox neurons (Fig. 2H). These results demonstrate that cortical neurons express $d n S N A R E$ in presence of Dox, but that the ${ }_{n}$ SNARE expression is increased after removal of Dox in dnSNARE mice. Therefore, the "Tet-Off" system under the control of the GFAP promoter regulates $d n S N A R E$ expression in cortical neurons in dnSNARE mice.

\section{Widespread neuronal expression of EGFP and $\beta$-gal in dnSNARE mice}

Immunohistochemical analysis in cerebral cortex confirmed that VAMP2 primarily colocalized with the neuronal marker microtubule associated protein 2 (MAP2; Fig. 3A). VAMP2 is mainly present in the presynaptic membrane or in dendrites and is thereby diffusely distributed in the neuropil. Immunostaining of cell cultures showed that MAP2-positive WT cortical neurons displayed intense VAMP2 labeling, whereas VAMP2 labeling in cultured cortical GFAP-positive WT astrocytes was low or absent (Fig. 3B). Therefore, this analysis confirmed that endogenous VAMP2, which mediates SNARE-dependent vesicular transmitter release, is highly enriched in neurons and expressed at much lower levels in astrocytes.

We next investigated whether the GFAP promoter drives the expression of the two reporter proteins EGFP and $\beta$-galactosidase ( $\beta$-gal) in dnSNARE mice. Strong EGFP expression was observed in dnSNARE mice under Off-Dox condition (Fig. 3C), which colocalized with GFAP-positive astrocytes in accordance with previous studies (Fellin et al., 2009; Halassa et al., 2009b). A low to moderate level of EGFP expression was also observed ubiquitously across most NeuN-positive neurons in cortex and hippocampus (Fig. 3C). EGFP expression was suppressed in dnSNARE mice under the On-Dox condition, but still remained as a broad, unspecific pattern of signals compared with WT mice, in which EGFP signal was absent. Surprisingly, GFAP-tTA negative mice, which lack GFAP-tTA gene but are positive for the tetO-dnSNARE gene, also showed similar EGFP expression (Fig. $3 C$ ), suggesting basal leakiness of the EGFP that is not under control of the promoter. We next detected the $\beta$-gal activity using $\mathrm{X}$-gal staining. NeuN-positive neurons in both cortex and hippocampus were also positive for $\beta$-gal in dnSNARE mice under the Off-Dox condition (Fig. 3D). WT mice were uniformly $\beta$-gal negative (Fig. $3 D$ ). Importantly, qPCR analysis of cortical tissue samples demonstrated that all 3 transgenes ( $m$ NSNARE, LacZ, and EGFP) were highly expressed in GFAP-tTA-negative mice, which are not supposed to express any transgene due to the lack of tTA (Fig. 3E). Similar unspecific leaky expressions of transgenes were also observed in On-Dox dnSNARE group (Fig. 3E). The 3 transgenes operate separately from one another, resulting in independent expression levels. Therefore, it was important to analyze each transgene separately. These analyses show the basal leakiness of "Tet-Off" system and that GFAP promoter drives transgene expression in neurons in dnSNARE mice. Therefore, direct suppression of neurotransmission via dnSNARE expressed in neurons might be responsible for the suppression of EEG signal during the Off-Dox condition.

To broaden our findings, we next investigated whether the GFAP promoter induces neuronal transgene expression in other 
A
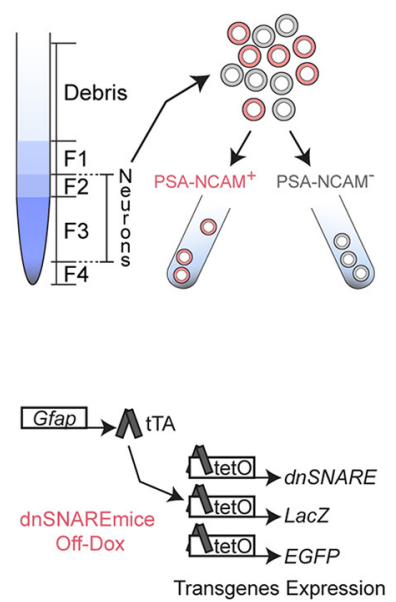

F

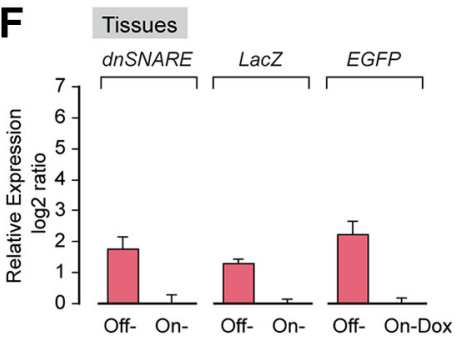

B
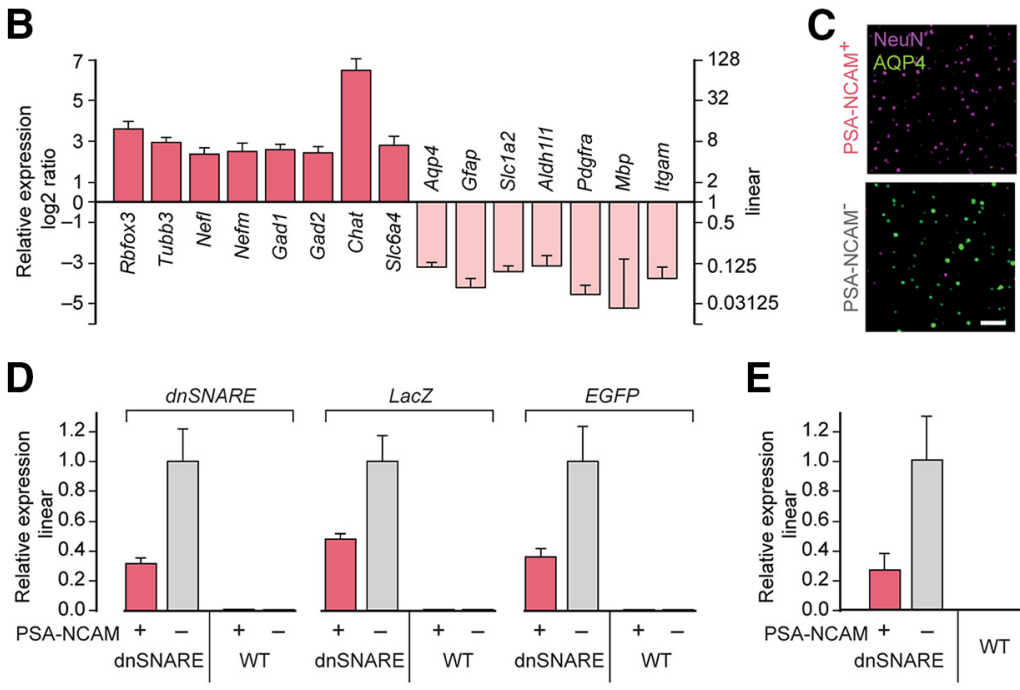

E

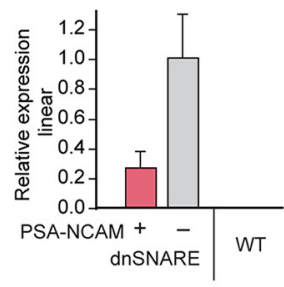

G

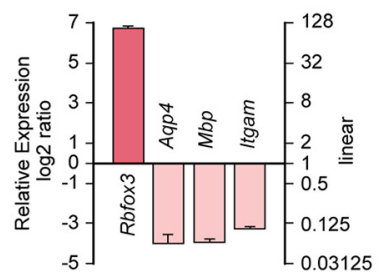

H Neurons

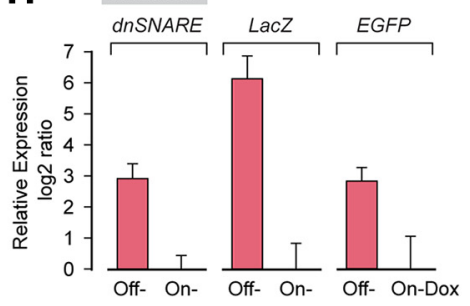

Figure 2. Neuronal expression of dnSNARE and 2 reporter genes LacZ and EGFP in dnSNARE mice. A, Top, Schematic outlining a collection of cortical neurons from 8-d old C57BL/6 WT or dnSNARE mice under Off-Dox condition using density gradient-based dissociation method and FACS. Neurons were enriched and separated from myelin debris by collecting Fraction 2 and 3 before FACS. Bottom, Under Off-Dox condition, human GFAP promoter drives the expression of 3 reporter units, dnSNARE, LacZ, and EGFP, in dnSNARE mice. $\boldsymbol{B}$, qPCR analysis of markers expression in purified mouse PSA-NCAM ${ }^{+}$population. Neuronal markers; RNA binding protein fox-1 homolog 3 (Rbfox3), Tubulin, beta 3 (Tubb3), Neurofilament, light polypeptide (Nefl), Neurofilament, medium polypeptide (Nefm), Glutamic acid decarboxylase 1 (Gad1), Glutamic acid decarboxylase 2 (Gad2), Choline acetyltransferase (Chat) and Solute carrier family 6, member 4 (SIc6a4). Astrocyte markers; Aquaporin 4 (Aqp4), Glial fibrillary acidic protein (Gfap), Excitatory amino acid transporter 2 (SIc1a2) and aldehyde dehydrogenase family 1, member L1 (Aldh 1/1). Oligodendrocyte precursor marker, platelet derived growth factor receptor, $\alpha$ polypeptide (Pdgfra). Oligodendrocyte marker, myelin basic protein (Mbp). Microglial marker, Integrin $\alpha$ M (Itgam). $n=7$ biological replicates. $C$, Immunolabeling analysis of neuronal marker expression in purified mouse PSA-NCAM ${ }^{+}$population. Neuronal marker NeuN is highly enriched in cortical PSA-NCAM ${ }^{+}$populations compared with

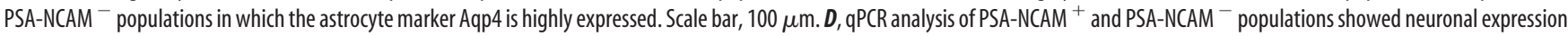
of dnSNARE and reporter transgenes (LacZ and EGFP) in dnSNARE mice ( $n=4$ biological samples) and no expression in both populations isolated from WT mice ( $n=3$ biological samples). $E$, Expression of the $t$ TA transgene in PSA-NCAM ${ }^{+}$and PSA-NCAM ${ }^{-}$populations in dnSNARE mice but not in WT mice ( $n=4$ each). $\boldsymbol{F}$, Relative expression of transgenes (dnSNARE, LacZ, and EGFP) in cerebral cortex in adult Off-Dox dnSNARE mice compared with On-Dox condition ( $n=4)$. G, Enrichment of neuronal marker gene Rbfox3 expression in neurons isolated from adult dnSNARE mice compared with tissue $(n=3)$. $\boldsymbol{H}$, Neuronal expression of transgenes (dnSNARE, LacZ, and EGFP) in adult dnSNARE mice under Off-Dox condition compared with On-Dox condition ( $n=3$ ). Error bars indicate SEM in $\boldsymbol{B}$ and $\boldsymbol{D}-\boldsymbol{H}$.

transgenic mice. We used a transgenic mouse line that expresses the Gi-coupled RASSL (receptor activated solely by synthetic ligand) Rol under the control of GFAP promoter using the "TetOff" system. Immunostaining of brain sections prepared from double-positive mice for both GFAP-tTA and tetO-Rol genes showed extensive neuronal expression of Rol in cortex and hippocampus (Fig. $3 F$ ). These results suggest that the lack of specificity of the GFAP promoter is not exclusive to dnSNARE mice.

\section{Normal sleep-wake cycle in dnSNARE mice}

The sleep-wake cycle is tightly regulated at the synaptic and cellular level (e.g., by transmitter release and cellular metabolic reserves) and is essential for basal brain functions such as memory consolidation and integration (Tononi and Cirelli, 2014) and glymphatic clearance (Xie et al., 2013). The sleep homeostatic factor adenosine was first shown to modulate sleep eight decades ago (Drury and Szent-Gyorgyi, 1929), and extracellular concentration of adenosine diurnally changes associated with the sleepwake cycle (Strecker et al., 2000; Murillo-Rodriguez et al., 2004). Prior analysis of dnSNARE mice has positioned adenosine as a central player in the pathways by which astrocytes modulate synaptic transmission (Pascual et al., 2005; Fellin et al., 2009; Halassa et al., 2009a; Halassa et al., 2009b; Halassa et al., 2010; Deng et al., 2011; Florian et al., 2011; Foley et al., 2011; Blutstein et al., 2012; Schmitt et al., 2012; Blutstein and Haydon, 2013; Hines et al., 2013; Nadjar et al., 2013). However, none of these studies has to our knowledge quantified the extracellular concentration of adenosine in vivo (Blutstein et al., 2012; Schmitt et al., 2012; Clasadonte et al., 2014). Here, we used microdialysis to collect samples of the extracellular fluid in either the basal forebrain or hippocampus in combination with chronic EEG recordings (Tian et al., 2005; Oberheim et al., 2008; Fig. 4A). Power spectrum analysis showed that, although the amplitude of the EEG signal was reduced in Off-Dox condition (Fig. 4B), both On-Dox and Off-Dox dnSNARE mice exhibited a normal sleep-wake cycle (Fig. $4 C$ ). Therefore, aside from the amplitude of the EEG signal, no significant change in sleep amount or quality was noted between the On-Dox and Off-Dox dnSNARE mice. During the transition to the light phase, the power of slow waves (delta waves) increased by $20.78 \pm 14.01 \%$ and $16.14 \pm 7.96 \%$ in On- 
A
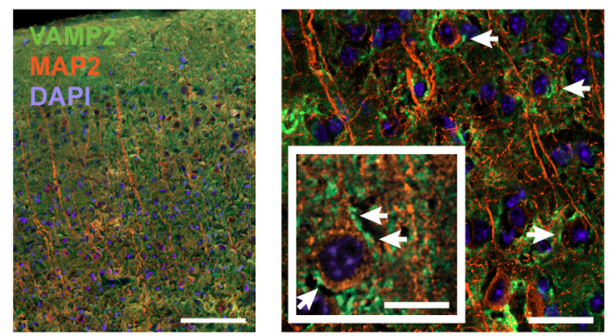

B
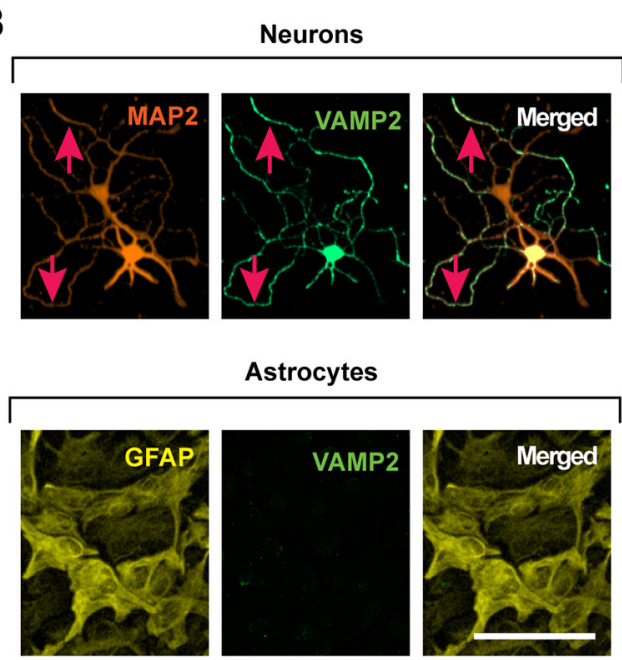

Astrocytes
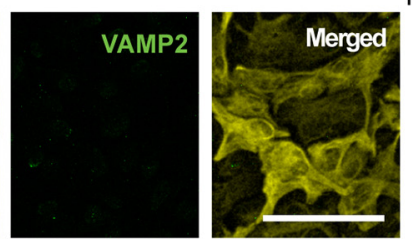

C
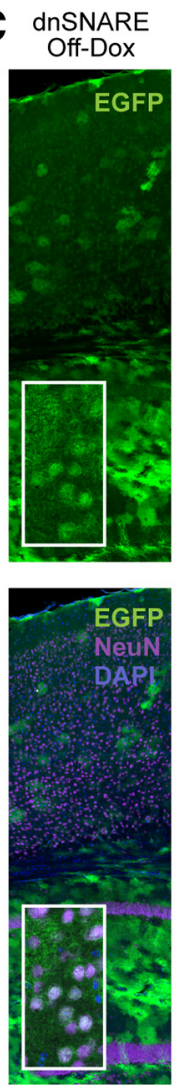
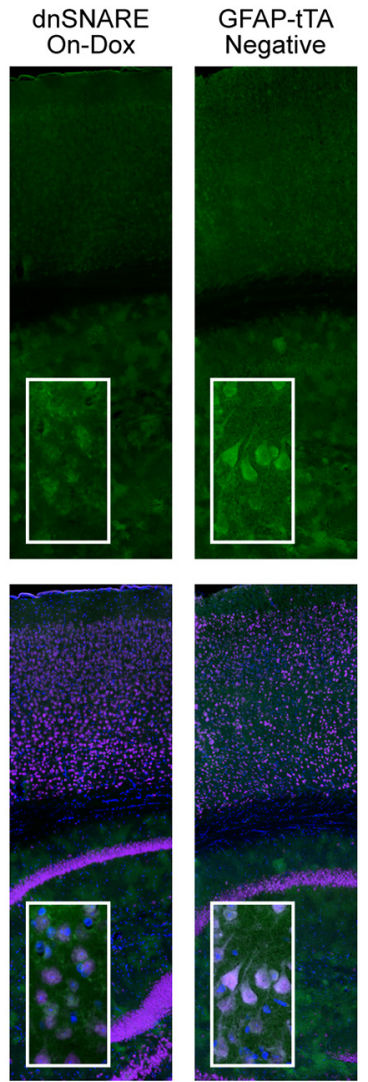

WT
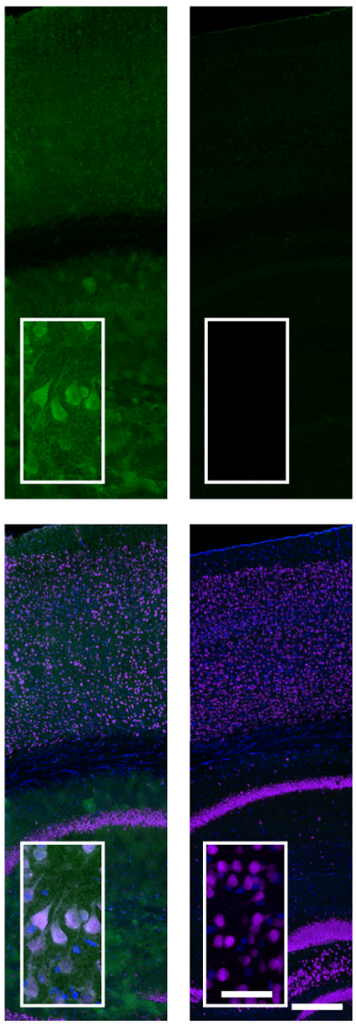

D

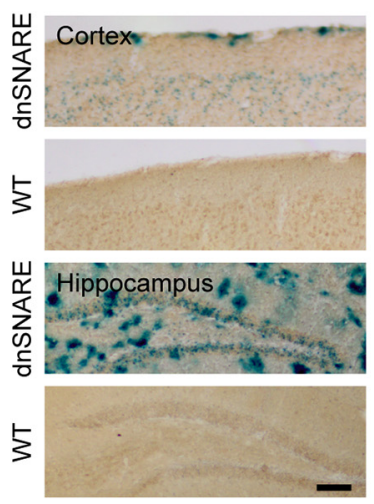

E

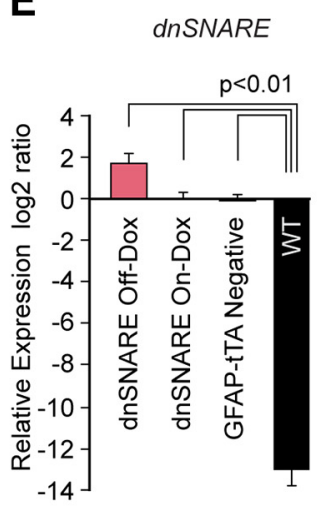

LacZ
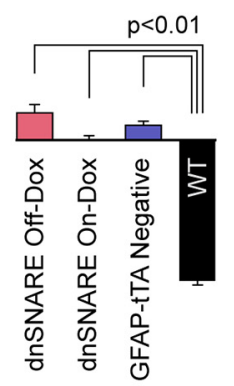

$\mathbf{F}$

EGFP

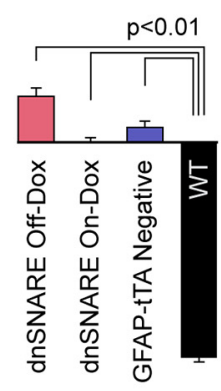

Cortex

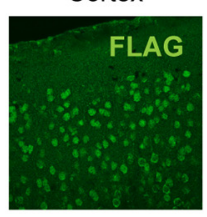

Hippocampus

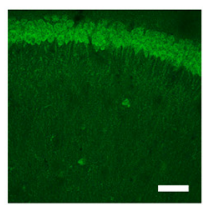

Figure 3. Expression of EGFP and $\beta$-galactosidase driven by GFAP promoter in widespread neuronal population and basal leakiness of "Tet-Off" system in dnSNARE mice. A, Immunohistochemical analysis of the cellular expression of VAMP2 in cerebral cortex (VAMP2, green; MAP2, orange; DAPI, blue). White arrows indicate VAMP2- and MAP2-positive neurons. Scale bars, $100 \mu \mathrm{m}$ (left), $20 \mu \mathrm{m}$ (right), $10 \mu \mathrm{m}$ (inset). $\boldsymbol{B}$, Analysis of VAMP2 expression in cortical astrocytic and cortical neuronal cultures. Immunocytochemistry for VAMP2 (green) together with MAP2 (orange) or GFAP (yellow). Red arrows indicate VAMP2- and MAP2-expressing cells. Scale bar, $100 \mu \mathrm{m}$. C, Neuronal EGFP expression in cortex and hippocampus. Unstained sagittal sections of dnSNARE 0ff-Dox, On-Dox, GFAP-tTA negative and wild-type C57BL/6J (WT) mice. Although scattered bright EGFP signals indicate a bushy astrocyte appearance in hippocampus and to a minor extend in cortex, NeuN-positive neurons (purple) also exhibit low to moderate level of EGFP expression throughout cortex and hippocampus in dnSNARE mice under the Off-Dox condition. EGFP expression is suppressed in On-Dox dnSNARE mice compared with that in the Off-Dox condition, but broad basal expression was observed. EGFP expression was also found in GFAP-tTA negative mice but was absent in WT mice. Insets are magnified images. Scale bars, $200 \mu \mathrm{m}$ (main images); $40 \mu \mathrm{m}$ (insets). $\boldsymbol{D}, X$-gal staining (blue) and NeuN immunohistochemistry (brown) shows that several neurons express $\beta$-galactosidase ( $\beta$-gal) in both cortex and hippocampus in dnSNARE Off-Dox mice. No $\beta$-gal positive cells were evident in WT mice. Scale bar, $100 \mu \mathrm{m}$. $E$, qPCR analysis of transgenes expressions (dnSNARE, LacZ, and EGFP) in cerebral cortex showing the leaky expressions of all 3 transgenes in adult GFAP-tTA-negative mice ( $n=4$, one-way ANOVA followed by Tukey-Kramer test). Error bars indicate SEM. $\boldsymbol{F}$, GFAP promoter induces neuronal expression of Gi-coupled RASSL (receptor activated solely by synthetic ligand) Ro1. Representative images collected from a double-transgenic mice line that expresses Ro1 under the control of GFAP promoter using "Tet-0ff" system. Ro1 expression was examined in brain sections prepared from Ro1 mice by immunostaining against FLAG (the epitope tag fused to Ro1). Majority of neurons express FLAG in both cortex and hippocampus. Scale bar, $50 \mu \mathrm{m}$.

Dox and Off-Dox dnSNARE animals, respectively. Concomitantly, a decrease in fast activity (alpha and beta waves) was noted in both the On-Dox and Off-Dox groups, consistent with the fact that mice are nocturnal and mostly sleep during the day (Fig. 4C).
HPLC analysis of the microdialysis samples revealed that the dark and light phases were accompanied by diurnal changes in the extracellular concentration of adenosine in basal forebrain (Strecker et al., 2000; Murillo-Rodriguez et al., 2004; Fig. 4D). 
A

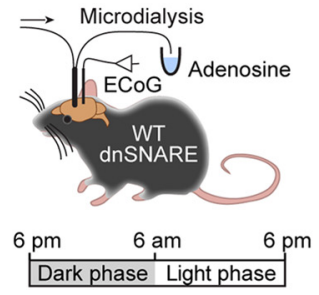

D

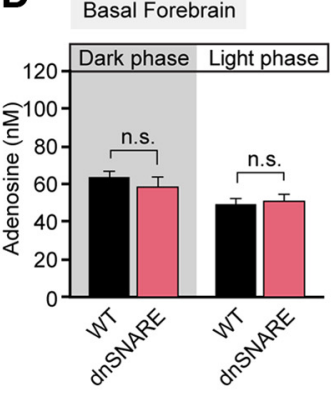

Hippocampus

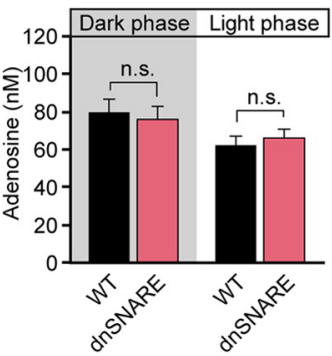

B

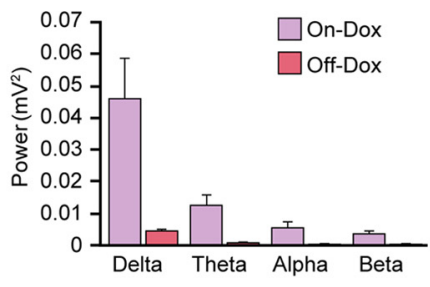

E

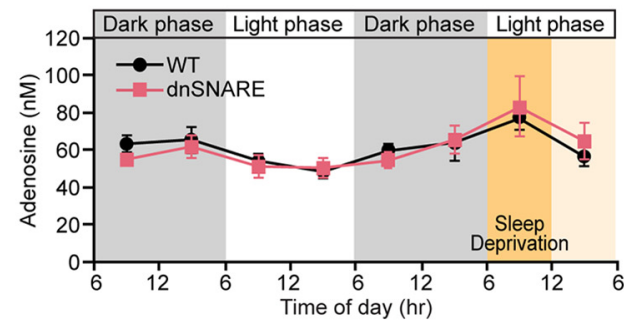

Hippocampus

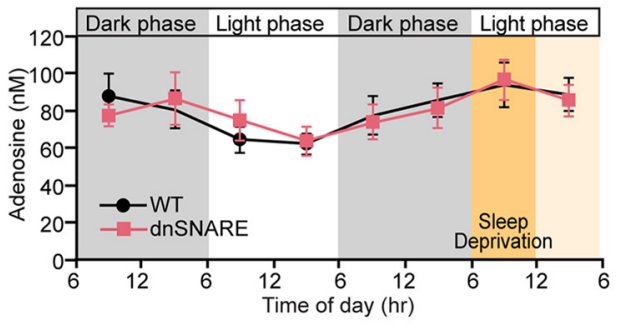

C
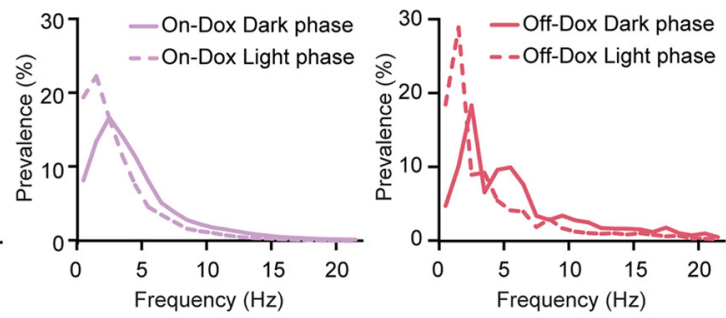

$\mathbf{F}$
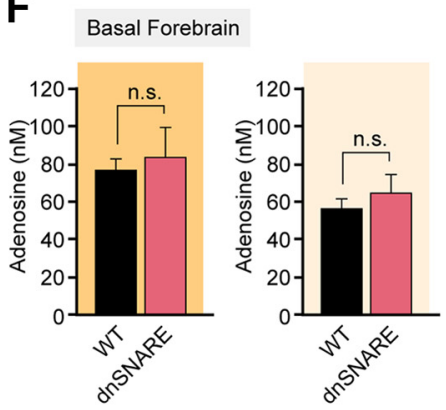

Hippocampus
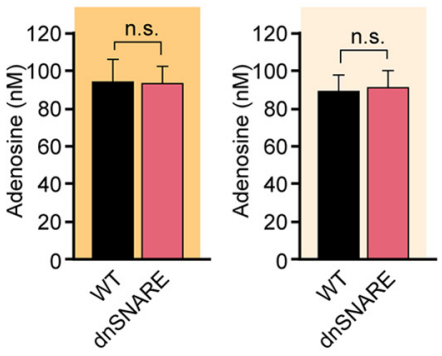

Figure 4. EEG activity pattern and adenosine follow a circadian rhythm in dnSNARE mice. $A$, Schematic diagram depicting how ECoG recordings and microdialysis samples were collected in freely moving mice. $B$, Comparison of the raw power spectrum of dnSNARE mice under Off-Dox and On-Dox conditions $(n=5)$. $C$, Representative power spectrum analysis show the shift in the percentage prevalence of delta waves between dark and light phase in On-Dox (left) and Off-Dox (right) conditions. D, Comparison of the extracellular concentration of adenosine in wild-type C57BL/6J (WT) and Off-Dox dnSNARE mice during the dark phase or light phase in basal forebrain (top, WT, $n=7 ;$ Off-Dox dnSNARE, $n=9$ ) or in hippocampus (bottom, WT, $n=9 ; 0$ off-Dox dnSNARE, $n=6 ; p>$ 0.05 , Student's $t$ test compared with WT). E, Adenosine measurements over $48 \mathrm{~h}$ in microdialysates collected before, during and after sleep deprivation from basal forebrain (top) and hippocampus (bottom) in WT (basal forebrain, $n=5$; hippocampus, $n=7$ ) and in Off-Dox dnSNARE mice (basal forebrain, $n=6$; hippocampus, $n=4$ ). $\boldsymbol{F}$, Adenosine concentrations during sleep deprivation and subsequent recovery sleep periods. No significant difference in adenosine concentrations was observed between WT and Off-Dox dnSNARE mice in either basal forebrain (top left, sleep deprivation period; top right, recovery sleep period; $n=5-6$ ) or hippocampus (bottom left, sleep deprivation period; bottom right, recovery sleep period; $n=5-8$ ). Error bars indicate SEM in $\boldsymbol{B}$ and D-F. n.S., Not significant.

Adenosine was consistently higher during the dark phase, when the mice were awake and physically active, in both the WT and Off-Dox dnSNARE groups. Conversely, adenosine was significantly lower during the light phase when the mice are mostly sleeping in both WT and dnSNARE mice under Off-Dox conditions. A similar pattern of changes in adenosine was noted during the sleep-wake cycle in hippocampus, although the adenosine concentration tended to be slightly higher in hippocampus (Fig. $4 D$ ). However, adenosine concentrations in WT and Off-Dox dnSNARE mice were almost identical in basal forebrain and in hippocampus, in which GFAP promoter is highly active in astrocytes and thus sufficient inhibition of SNARE-dependent gliotransmitter release is expected. Because the basal leaky expression of transgenes (dnSNARE, LacZ, and EGFP) was observed in OnDox dnSNARE mice (Fig. 3E), we also collected microdialysates from On-Dox dnSNARE mice. Notably, no differences in the extracellular concentration of adenosine in hippocampus were observed during the dark phase in Off-Dox and On-Dox dnSNARE mice compared with WT mice $(n=5-10$; Off-Dox, $78.3 \pm 5.95$; On-Dox, $82.2 \pm 14.43$; WT, $84.0 \pm 9.87 \mathrm{~nm} ; p>$
0.05, one-way ANOVA). Therefore, this analysis shows that sleep-wake rhythmic changes in extracellular concentration of adenosine are not controlled by expression of dnSNARE under the GFAP promoter.

Previous studies have shown that accumulation of sleep pressure, assessed as the relative power of slow-wave activity during rebound sleep period subsequent to sleep deprivation, is reduced in dnSNARE mice and thus might be mediated by an inhibition of SNARE-dependent adenosine release from astrocytes (Halassa et al., 2009b). To assess this finding, we monitored adenosine concentrations during the normal sleep-wake cycle, followed by $6 \mathrm{~h}$ of sleep deprivation and subsequent recovery sleep. The extracellular concentration of adenosine in Off-Dox dnSNARE mice did not differ from WT mice in either basal forebrain or hippocampus. In fact, the extracellular concentration of adenosine during the normal sleep-wake cycle, during sleep deprivation, and during recovery sleep in dnSNARE mice under Off-Dox condition closely mimicked previous observations in wild-type animals (Strecker et al., 2000; Blanco-Centurion et al., 2006; Murillo-Rodriguez et al., 2008; Fig. 4E). Sleep deprivation signif- 
icantly increased the extracellular adenosine concentration compared with WT mice without sleep deprivation in both basal forebrain $(n=5-7, p=0.036, t$ test compared with 6:00 A.M. to $\sim 12$ :00 P.M. in the undisturbed condition) and hippocampus ( $n=7-9, p=0.028, t$ test). Similarly, sleep-deprivation-induced adenosine increase was also observed in Off-Dox dnSNARE mice in both basal forebrain $(n=6-9, p=0.033, t$ test compared with 6:00 A.M. to $\sim 12: 00$ P.M. in the undisturbed condition) and hippocampus ( $n=8-9, p=0.031, t$ test). No difference in adenosine concentration was observed between WT and Off-Dox dnSNARE mice during sleep deprivation and subsequent rebound sleep periods (Fig. $4 F$ ). Therefore, direct measurements of adenosine in the basal forebrain and hippocampus provided no support to the idea that adenosine signaling differs in Off-Dox dnSNARE mice.

\section{Discussion}

This study shows that the GFAP promoter drives inducible expression of $d n S N A R E$ and 2 reporter transgenes not only in astrocytes, but also in neuronal populations in cerebral cortex of adult mice (Figs. 2 and 3). Bigenic dnSNARE mice are generated by crossing GFAP-tTA mice with tetO-dnSNARE mice. In the absence of Dox, SNARE-dependent vesicular release is inhibited in dnSNARE mice by expression of a dominant-negative domain of vesicular SNARE, VAMP2/synaptobrevin 2 (Pascual et al., 2005). Global deletion of VAMP2 potently suppresses synaptic transmission and is lethal in embryonic stages because the SNARE complex is essential for membrane insertion of synaptic vesicles in forebrain neurons (Schoch et al., 2001). We here found that cortical EEG was reversibly controlled by administration of Dox in dnSNARE mice (Fig. 1). When Dox was present, the binding affinity of tTA to tetO is reduced (Takahashi et al., 1986) and therefore transcription of the dnSNARE transgene is suppressed, resulting in normal EEG power. However, removal of Dox induces the transcription of dnSNARE and suppression of the EEG signal amplitude. Our observation is a direct extension of earlier work showing that the constitutive GFAP promoter drives transgene expression in multiple neuronal populations when active during development (Zhuo et al., 2001; Su et al., 2004) and revalidating the importance of detailed analysis of cell specificity (Barres, 2003). The GFAP-tTA line uses the same human GFAP promoter (gfa2) that Brenner's group originally created (Brenner et al., 1994) and later showed to be leaky when constitutively expressed because it drives transgene expression in neurons in nonconditional transgenic mice (Zhuo et al., 2001; Su et al., 2004).

Our finding has implications for a number of interrelated topics, including neuroglia signaling, sleep-wake cycle, and synaptic plasticity because previous analyses of dnSNARE transgenic mice have suggested that astrocytes participate in these complex neural processes by regulation of extracellular adenosine (Halassa et al., 2009b). Adenosine is a largely inhibitory neuromodulator that plays a neuroprotective role in several pathophysiological conditions, including seizure, ischemic stroke, chronic pain, and traumatic brain injury (Chen et al., 1999; Fredholm et al., 2005; Chen et al., 2007; Boison, 2008; Boison et al., 2010; Goldman et al., 2010; Boison, 2012). Based on our observations reported here, it is important that properties of astrocytes and their possible roles in neural processes (Pascual et al., 2005; Fellin et al., 2009; Halassa et al., 2009a; Halassa et al., 2009b; Halassa et al., 2010; Deng et al., 2011; Florian et al., 2011; Foley et al., 2011; Blutstein et al., 2012; Lee et al., 2012; Schmitt et al., 2012; Turner et al., 2012; Clasadonte et al., 2013; Hines et al., 2013; Nadjar et al., 2013;
Kawamata et al., 2014; Lalo et al., 2014) be reassessed using an approach that does not depend on the GFAP promoter. Herein, we limit the analysis to explore the postulate that dnSNARE regulates the extracellular concentration of adenosine (Fig. 4), but failed to confirm the existence of a SNARE-dependent mechanism controlling adenosine. What, then, could account for the reduced sleep pressure observed in Off-Dox dnSNARE mice? One possibility is that the profound suppression of synaptic transmission in Off-Dox dnSNARE mice directly reduces sleep pressure. Other more complex mechanisms may involve changes in neuromodulator-mediated regulation of the sleep-wake cycle. In addition to the importance of VAMP2 in glutamatergic and GABAergic transmission, prior studies have implicated VAMP2 in neuromodulator release (Yang et al., 2007).

Several prior studies used adenosine biosensors to record the extracellular concentration of adenosine in acute slices prepared from dnSNARE mice and reported that dnSNARE expression reduces the extracellular adenosine concentration (Blutstein et al., 2012; Schmitt et al., 2012). In this regard, it is important to note that our in vivo measurement detected adenosine concentration in the range of $40-100 \mathrm{nM}$ consistent with the reports of 60-120 nm (Strecker et al., 2000) and 40-140 nm in rats (MurilloRodriguez et al., 2004) and 10-40 nM in humans (Zeitzer et al., 2006). In contrast, adenosine concentrations of 600-3200 nM were recorded at the surface of acute vibratome slices with adenosine biosensors (Schmitt et al., 2012). These concentrations are 6- to 80 -fold higher than the extracellular adenosine concentration in vivo. The higher adenosine concentration ex vivo may reflect that preparation of vibratome sections or acute insertion of adenosine biosensors into the tissue triggers a dramatic rise in the extracellular adenosine concentration and that one or several steps in the purine metabolism are sensitive to dnSNARE expression. Adenosine increases from a baseline concentration of 130 nM to $1200 \mathrm{~nm}$ during ischemia (Melani et al., 2012) and to a peak of $8340 \mathrm{nM}$ in a model of experimental traumatic brain injury (Bell et al., 1998). Because vibratome sections have been exposed to both global ischemia (decapitation) and traumatic injury (vibratome cutting), it is possible that ischemia and traumatic injury both contribute to the striking difference in adenosine concentration ex vivo versus in vivo.

Our study highlights the necessity for careful analysis of the cell specificity of transgene expression in conditional mouse models. Although the study from the Brenner group questioned the astrocytic specificity of their own promoter in 2004, >200 studies have since been published based on conditional manipulation of genes driven by the GFAP promoter without the detailed analysis of the cell specificity (Brenner et al., 1994; Zhuo et al., 2001; Su et al., 2004). Neuronal expression of target genes/proteins may also be found in other adult transgenic mice using the GFAP promoter, especially when it is combined with the "TetOff" system. In fact, our analysis showed that another transgenic mouse line, GFAP-tTA:tetO-Ro1, also displayed leaky neuronal expression of Rol at the protein level (Fig. $3 F$ ). Because the specificity of the GFAP promoter may vary in different founders and in different transgenic systems, our findings suggest that the detailed evaluation of each transgenic mouse using the GFAP promoter may be necessary to ensure the desired expression profile. The leakiness will likely depend on the site of integration in each founder line. For example, if the GFAP promoter integrates in a locus that is highly active in neurons, the probability of leaky expression will be higher than in another mouse with integration in a quiet locus. In principle, the lack of astrocytic specificity of the GFAP promoter questions the conclusion of all earlier re- 
ports. The leakiness of the GFAP promoter may, however, have especially pronounced effects in the dnSNARE mice, because VAMP2 is primarily expressed by neurons (Fig. $3 A, B$ ) and furthermore plays a critical role in synaptic transmission in forebrain (Schoch et al., 2001). Our analysis clearly showed that $d n S N A R E$ was expressed in cortical neurons (32\% of that in glial population; Fig. $2 D$ ) and that neuronal $d n S N A R E$ expression was sensitive to doxycycline (Off-Dox versus On-Dox comparison in Fig. $2 H$ ). Moreover, $t$ TA was also expressed by neurons under the control of the GFAP promoter in $d n S N A R E$ mice (Fig. $2 E$ ). These results show that the GFAP promoter induced the $d n S N A R E$ expression in neurons via a "Tet-Off" system. Recent studies have proposed the use of other astrocyte-specific promoters including the sodium-dependent glutamate/aspartate transporter GLAST, connexin 30, and the aldehyde dehydrogenase 1 family member L1 ALDH1L1 (Slezak et al., 2007; Cahoy et al., 2008), which are more stably expressed by astrocytes in adult brain compared with GFAP (Söhl et al., 2000) and overcomes the typical problem of low transgene expression levels in astrocytes in cerebral cortex with GFAP promoter (Palfreyman et al., 1979; Jany et al., 2013). Another important aspect is the broad basal leaky expression of dnSNARE found in the mice that are negative for GFAPtTA gene and only positive for tetO-dnSNARE gene, in which dnSNARE expression should not be induced because of the lack of tTA (Fig. 3E). This conclusion is consistent with prior reports demonstrating that early generations of tetracyclinetransregulatable systems, including the "Tet-Off" system, were plagued by high basal leakiness, unpredictable transgene expression, and loss of regulation (Agha-Mohammadi et al., 2004; Liu et al., 2008; Nishijima et al., 2009). Subsequent modifications attenuated leakiness by incorporating tetracycline-controlled transcriptional silencers (Zhu et al., 2002) and the use of these improved systems may be required for generating future inducible transgenic mice lines.

Combined, our analysis provided no evidence for the concept that astrocytes regulate neuronal activity and the sleep-wake cycle by exocytotic release of purines. In fact, collection of the interstitial fluid using microdialysis showed that the extracellular concentration of adenosine in dnSNARE mice in vivo did not differ from controls. These observations add critical additional evidence against the concept of regulated exocytotic gliotransmitter release in the adult brain (Lovatt et al., 2012; Nedergaard and Verkhratsky, 2012; Sun et al., 2013). Future studies must overcome methodological and developmental issues to establish the complex roles of astrocytes in higher cognitive functions in the adult brain.

\section{References}

Agha-Mohammadi S, O’Malley M, Etemad A, Wang Z, Xiao X, Lotze MT (2004) Second-generation tetracycline-regulatable promoter: repositioned tet operator elements optimize transactivator synergy while shorter minimal promoter offers tight basal leakiness. J Gene Med 6:817828. CrossRef Medline

Agulhon C, Petravicz J, McMullen AB, Sweger EJ, Minton SK, Taves SR, Casper KB, Fiacco TA, McCarthy KD (2008) What is the role of astrocyte calcium in neurophysiology? Neuron 59:932-946. CrossRef Medline

Araque A, Carmignoto G, Haydon PG, Oliet SH, Robitaille R, Volterra A (2014) Gliotransmitters travel in time and space. Neuron 81:728-739. CrossRef Medline

Barker JM, Torregrossa MM, Taylor JR (2012) Low prefrontal PSA-NCAM confers risk for alcoholism-related behavior. Nat Neurosci 15:1356-1358. CrossRef Medline

Barres BA (2003) What is a glial cell? Glia 43:4-5. CrossRef Medline

Barres BA (2008) The mystery and magic of glia: a perspective on their roles in health and disease. Neuron 60:430-440. CrossRef Medline
Barton MD, Dunlop JW, Psaltis G, Kulik J, DeGennaro L, Kwak SP (2002) Modified GFAP promoter auto-regulates tet-activator expression for increased transactivation and reduced tTA-associated toxicity. Brain Res Mol Brain Res 101:71-81. CrossRef Medline

Bell MJ, Kochanek PM, Carcillo JA, Mi Z, Schiding JK, Wisniewski SR, Clark RS, Dixon CE, Marion DW, Jackson E (1998) Interstitial adenosine, inosine, and hypoxanthine are increased after experimental traumatic brain injury in the rat. J Neurotrauma 15:163-170. CrossRef Medline

Blanco-Centurion C, Xu M, Murillo-Rodriguez E, Gerashchenko D, Shiromani AM, Salin-Pascual RJ, Hof PR, Shiromani PJ (2006) Adenosine and sleep homeostasis in the Basal forebrain. J Neurosci 26:8092-8100. CrossRef Medline

Blutstein T, Haydon PG (2013) The Importance of astrocyte-derived purines in the modulation of sleep. Glia 61:129-139. CrossRef Medline

Blutstein T, Schmitt LI, Haydon PG (2012) State-dependent changes in adenosine in the rodent hippocampus rely on gliotransmission. Program No. 486.14. 2012 Neuroscience Meeting Planner. New Orleans, LA: Society for Neuroscience.

Boison D (2008) Adenosine as a neuromodulator in neurological diseases. Curr Opin Pharmacol 8:2-7. CrossRef Medline

Boison D (2012) Adenosine dysfunction in epilepsy. Glia 60:1234-1243. CrossRef Medline

Boison D, Chen JF, Fredholm BB (2010) Adenosine signaling and function in glial cells. Cell Death Differ 17:1071-1082. CrossRef Medline

Brenner M, Kisseberth WC, Su Y, Besnard F, Messing A (1994) GFAP promoter directs astrocyte-specific expression in transgenic mice. J Neurosci 14:1030-1037. Medline

Brewer GJ, Torricelli JR (2007) Isolation and culture of adult neurons and neurospheres. Nat Protoc 2:1490-1498. CrossRef Medline

Cahoy JD, Emery B, Kaushal A, Foo LC, Zamanian JL, Christopherson KS, Xing Y, Lubischer JL, Krieg PA, Krupenko SA, Thompson WJ, Barres BA (2008) A transcriptome database for astrocytes, neurons, and oligodendrocytes: a new resource for understanding brain development and function. J Neurosci 28:264-278. CrossRef Medline

Chen JF, Huang Z, Ma J, Zhu J, Moratalla R, Standaert D, Moskowitz MA, Fink JS, Schwarzschild MA (1999) A(2A) adenosine receptor deficiency attenuates brain injury induced by transient focal ischemia in mice. J Neurosci 19:9192-9200. Medline

Chen JF, Sonsalla PK, Pedata F, Melani A, Domenici MR, Popoli P, Geiger J, Lopes LV, de Mendonça A (2007) Adenosine A2A receptors and brain injury: broad spectrum of neuroprotection, multifaceted actions and "fine tuning" modulation. Prog Neurobiol 83:310-331. CrossRef Medline

Clasadonte J, Dong J, Hines DJ, Haydon PG (2013) Astrocyte control of synaptic NMDA receptors contributes to the progressive development of temporal lobe epilepsy. Proc Natl Acad Sci U S A 110:17540-17545. CrossRef Medline

Clasadonte J, McIver SR, Schmitt LI, Halassa MM, Haydon PG (2014) Chronic sleep restriction disrupts sleep homeostasis and behavioral sensitivity to alcohol by reducing the extracellular accumulation of adenosine. J Neurosci 34:1879-1891. CrossRef Medline

Deng Q, Terunuma M, Fellin T, Moss SJ, Haydon PG (2011) Astrocytic activation of Al receptors regulates the surface expression of NMDA receptors through a Src kinase-dependent pathway. Glia 59:1084-1093. CrossRef Medline

Drury AN, Szent-Györgyi A (1929) The physiological activity of adenine compounds with especial reference to their action upon the mammalian heart. J Physiol 68:213-237. Medline

Fellin T, Halassa MM, Terunuma M, Succol F, Takano H, Frank M, Moss SJ, Haydon PG (2009) Endogenous nonneuronal modulators of synaptic transmission control cortical slow oscillations in vivo. Proc Natl Acad Sci U S A 106:15037-15042. CrossRef Medline

Florian C, Vecsey CG, Halassa MM, Haydon PG, Abel T (2011) Astrocytederived adenosine and Al receptor activity contribute to sleep lossinduced deficits in hippocampal synaptic plasticity and memory in mice. J Neurosci 31:6956-6962. CrossRef Medline

Foley JC, McIver SR, Haydon PG (2011) Gliotransmission modulates baseline mechanical nociception. Mol Pain 7:93. CrossRef Medline

Fredholm BB, Chen JF, Masino SA, Vaugeois JM (2005) Actions of adenosine at its receptors in the CNS: insights from knockouts and drugs. Annu Rev Pharmacol Toxicol 45:385-412. CrossRef Medline

Fujita T, Williams EK, Jensen TK, Smith NA, Takano T, Tieu K, Nedergaard 
M (2012) Cultured astrocytes do not release adenosine during hypoxic conditions. J Cereb Blood Flow Metab 32:e1-7. CrossRef Medline

Goldman N, Chen M, Fujita T, Xu Q, Peng W, Liu W, Jensen TK, Pei Y, Wang F, Han X, Chen JF, Schnermann J, Takano T, Bekar L, Tieu K, Nedergaard M (2010) Adenosine Al receptors mediate local anti-nociceptive effects of acupuncture. Nat Neurosci 13:883-888. CrossRef Medline

Gómez-Climent MÁ, Guirado R, Castillo-Gómez E, Varea E, GutierrezMecinas M, Gilabert-Juan J, García-Mompó C, Vidueira S, SanchezMataredona D, Hernández S, Blasco-Ibáñez JM, Crespo C, Rutishauser U, Schachner M, Nacher J (2011) The polysialylated form of the neural cell adhesion molecule (PSA-NCAM) is expressed in a subpopulation of mature cortical interneurons characterized by reduced structural features and connectivity. Cereb Cortex 21:1028-1041. CrossRef Medline

Gourine AV, Kasparov S (2011) Astrocytes as brain interoceptors. Exp Physiol 96:411-416. CrossRef Medline

Halassa MM, Fellin T, Haydon PG (2009a) Tripartite synapses: roles for astrocytic purines in the control of synaptic physiology and behavior. Neuropharmacology 57:343-346. CrossRef Medline

Halassa MM, Florian C, Fellin T, Munoz JR, Lee SY, Abel T, Haydon PG, Frank MG (2009b) Astrocytic modulation of sleep homeostasis and cognitive consequences of sleep loss. Neuron 61:213-219. CrossRef Medline

Halassa MM, Dal Maschio M, Beltramo R, Haydon PG, Benfenati F, Fellin T (2010) Integrated brain circuits: neuron-astrocyte interaction in sleeprelated rhythmogenesis. ScientificWorldJournal 10:1634-1645. CrossRef Medline

Hines DJ, Haydon PG (2013) Inhibition of a SNARE-sensitive pathway in astrocytes attenuates damage following stroke. J Neurosci 33:4234-4240. CrossRef Medline

Hines DJ, Schmitt LI, Hines RM, Moss SJ, Haydon PG (2013) Antidepressant effects of sleep deprivation require astrocyte-dependent adenosine mediated signaling. Transl Psychiatry 3:e212. CrossRef Medline

Jany PL, Hagemann TL, Messing A (2013) GFAP expression as an indicator of disease severity in mouse models of Alexander disease. ASN Neuro 5:e00109. Medline

Kawamata H, Ng SK, Diaz N, Burstein S, Morel L, Osgood A, Sider B, Higashimori H, Haydon PG, Manfredi G, Yang Y (2014) Abnormal intracellular calcium signaling and SNARE-dependent exocytosis contributes to SOD1G93A astrocyte-mediated toxicity in amyotrophic lateral sclerosis. J Neurosci 34:2331-2348. CrossRef Medline

Lalo U, Palygin O, Rasooli-Nejad S, Andrew J, Haydon PG, Pankratov Y (2014) Exocytosis of ATP from astrocytes modulates phasic and tonic inhibition in the neocortex. PLoS Biol 12:e1001747. CrossRef Medline

Lee H, Wake H, Lee PR, Fields RD (2012) SNARE-dependent vesicular release of neuroactive molecules from astrocytes modulates the structure of the node of Ranvier. Program No. 848.08. 2012 Neuroscience Meeting Planner. New Orleans, LA: Society for Neuroscience.

Lin JH, Weigel H, Cotrina ML, Liu S, Bueno E, Hansen AJ, Hansen TW, Goldman S, Nedergaard M (1998) Gap-junction-mediated propagation and amplification of cell injury. Nat Neurosci 1:494-500. CrossRef Medline

Liu B, Wang S, Brenner M, Paton JF, Kasparov S (2008) Enhancement of cell-specific transgene expression from a Tet-Off regulatory system using a transcriptional amplification strategy in the rat brain. J Gene Med 10: 583-592. CrossRef Medline

Lovatt D, Xu Q, Liu W, Takano T, Smith NA, Schnermann J, Tieu K, Nedergaard M (2012) Neuronal adenosine release, and not astrocytic ATP release, mediates feedback inhibition of excitatory activity. Proc Natl Acad Sci U S A 109:6265-6270. CrossRef Medline

Melani A, Corti F, Stephan H, Müller CE, Donati C, Bruni P, Vannucchi MG, Pedata F (2012) Ecto-ATPase inhibition: ATP and adenosine release under physiological and ischemic in vivo conditions in the rat striatum. Exp Neurol 233:193-204. CrossRef Medline

Murillo-Rodriguez E, Blanco-Centurion C, Gerashchenko D, Salin-Pascual RJ, Shiromani PJ (2004) The diurnal rhythm of adenosine levels in the basal forebrain of young and old rats. Neuroscience 123:361-370. CrossRef Medline

Murillo-Rodriguez E, Liu M, Blanco-Centurion C, Shiromani PJ (2008) Effects of hypocretin (orexin) neuronal loss on sleep and extracellular adenosine levels in the rat basal forebrain. Eur J Neurosci 28:1191-1198. CrossRef Medline

Nadjar A, Blutstein T, Aubert A, Laye S, Haydon PG (2013) Astrocyte- derived adenosine modulates increased sleep pressure during inflammatory response. Glia 61:724-731. CrossRef Medline

Nedergaard M, Verkhratsky A (2012) Artifact versus reality-how astrocytes contribute to synaptic events. Glia 60:1013-1023. CrossRef Medline

Nedergaard M, Takano T, Hansen AJ (2002) Beyond the role of glutamate as a neurotransmitter. Nat Rev Neurosci 3:748-755. CrossRef Medline

Nishijima H, Yasunari T, Nakayama T, Adachi N, Shibahara K (2009) Improved applications of the tetracycline-regulated gene depletion system. Biosci Trends 3:161-167. Medline

Oberheim NA, Tian GF, Han X, Peng W, Takano T, Ransom B, Nedergaard M (2008) Loss of astrocytic domain organization in the epileptic brain. J Neurosci 28:3264-3276. CrossRef Medline

Palfreyman JW, Thomas DG, Ratcliffe JG, Graham DI (1979) Glial fibrillary acidic protein (GFAP): purification from human fibrillary astrocytoma, development and validation of a radioimmunoassay for GFAP-like immunoactivity. J Neurol Sci 41:101-113. CrossRef Medline

Pascual O, Casper KB, Kubera C, Zhang J, Revilla-Sanchez R, Sul JY, Takano H, Moss SJ, McCarthy K, Haydon PG (2005) Astrocytic purinergic signaling coordinates synaptic networks. Science 310:113-116. CrossRef Medline

Schmidt MA, Wisor JP (2012) Interleukin 1 receptor contributes to methamphetamine- and sleep deprivation-induced hypersomnolence. Neurosci Lett 513:209-213. CrossRef Medline

Schmitt LI, Sims RE, Dale N, Haydon PG (2012) Wakefulness affects synaptic and network activity by increasing extracellular astrocyte-derived adenosine. J Neurosci 32:4417-4425. CrossRef Medline

Schoch S, Deák F, Königstorfer A, Mozhayeva M, Sara Y, Südhof TC, Kavalali ET (2001) SNARE function analyzed in synaptobrevin/VAMP knockout mice. Science 294:1117-1122. CrossRef Medline

Seki T (2002) Expression patterns of immature neuronal markers PSANCAM, CRMP-4 and NeuroD in the hippocampus of young adult and aged rodents. J Neurosci Res 70:327-334. CrossRef Medline

Slezak M, Göritz C, Niemiec A, Frisén J, Chambon P, Metzger D, Pfrieger FW (2007) Transgenic mice for conditional gene manipulation in astroglial cells. Glia 55:1565-1576. CrossRef Medline

Söhl G, Güldenagel M, Beck H, Teubner B, Traub O, Gutiérrez R, Heinemann U, Willecke K (2000) Expression of connexin genes in hippocampus of kainate-treated and kindled rats under conditions of experimental epilepsy. Brain Res Mol Brain Res 83:44-51. CrossRef Medline

Strecker RE, Morairty S, Thakkar MM, Porkka-Heiskanen T, Basheer R, Dauphin LJ, Rainnie DG, Portas CM, Greene RW, McCarley RW (2000) Adenosinergic modulation of basal forebrain and preoptic/anterior hypothalamic neuronal activity in the control of behavioral state. Behav Brain Res 115:183-204. CrossRef Medline

Su M, Hu H, Lee Y, d'Azzo A, Messing A, Brenner M (2004) Expression specificity of GFAP transgenes. Neurochem Res 29:2075-2093. CrossRef Medline

Sun W, McConnell E, Pare JF, Xu Q, Chen M, Peng W, Lovatt D, Han X, Smith Y, Nedergaard M (2013) Glutamate-dependent neuroglial calcium signaling differs between young and adult brain. Science 339:197200. CrossRef Medline

Sweger EJ, Casper KB, Scearce-Levie K, Conklin BR, McCarthy KD (2007) Development of hydrocephalus in mice expressing the $\mathrm{G}(\mathrm{i})$-coupled GPCR Ro1 RASSL receptor in astrocytes. J Neurosci 27:2309-2317. CrossRef Medline

Tafoya LC, Mameli M, Miyashita T, Guzowski JF, Valenzuela CF, Wilson MC (2006) Expression and function of SNAP-25 as a universal SNARE component in GABAergic neurons. J Neurosci 26:7826-7838. CrossRef Medline

Takahashi M, Altschmied L, Hillen W (1986) Kinetic and equilibrium characterization of the Tet repressor-tetracycline complex by fluorescence measurements: evidence for divalent metal ion requirement and energy transfer. J Mol Biol 187:341-348. CrossRef Medline

Takano T, Chen X, Luo F, Fujita T, Ren Z, Goldman N, Zhao Y, Markman JD, Nedergaard M (2012) Traditional acupuncture triggers a local increase in adenosine in human subjects. J Pain 13:1215-1223. CrossRef Medline

Tian GF, Azmi H, Takano T, Xu Q, Peng W, Lin J, Oberheim N, Lou N, Wang X, Zielke HR, Kang J, Nedergaard M (2005) An astrocytic basis of epilepsy. Nat Med 11:973-981. CrossRef Medline

Tononi G, Cirelli C (2014) Sleep and the price of plasticity: from synaptic and cellular homeostasis to memory consolidation and integration. Neuron 81:12-34. CrossRef Medline 
Turner JR, Ecke LE, Briand LA, Haydon PG, Blendy JA (2012) Cocainerelated behaviors in mice with deficient gliotransmission. Psychopharmacology (Berl) 226:167-176. CrossRef Medline

Volterra A, Liaudet N, Savtchouk I (2014) Astrocyte $\mathrm{Ca}(2+)$ signalling: an unexpected complexity. Nat Rev Neurosci 15:327-335. CrossRef Medline

Wisor JP, Clegern WC (2011) Quantification of short-term slow wave sleep homeostasis and its disruption by minocycline in the laboratory mouse. Neurosci Lett 490:165-169. CrossRef Medline

Wisor JP, Clegern WC, Schmidt MA (2011) Toll-like receptor 4 is a regulator of monocyte and electroencephalographic responses to sleep loss. Sleep 34:1335-1345. CrossRef Medline

Xie L, Kang H, Xu Q, Chen MJ, Liao Y, Thiyagarajan M, O’Donnell J, Christensen DJ, Nicholson C, Iliff JJ, Takano T, Deane R, Nedergaard M (2013) Sleep drives metabolite clearance from the adult brain. Science 342:373-377. CrossRef Medline

Yang J, Teng Q, Garrity-Moses ME, McClelland S 3rd, Federici T, Carlton E, Riley J, Boulis NM (2007) Reversible unilateral nigrostriatal pathway inhibition induced through expression of adenovirus-mediated clostridial light chain gene in the substantia nigra. Neuromolecular Med 9:276284. CrossRef Medline

Zeitzer JM, Morales-Villagran A, Maidment NT, Behnke EJ, Ackerson LC, Lopez-Rodriguez F, Fried I, Engel J Jr, Wilson CL (2006) Extracellular adenosine in the human brain during sleep and sleep deprivation: an in vivo microdialysis study. Sleep 29:455-461. Medline

Zhang Q, Pangrsic T, Kreft M, Krzan M, Li N, Sul JY, Halassa M, Van Bockstaele E, Zorec R, Haydon PG (2004) Fusion-related release of glutamate from astrocytes. J Biol Chem 279:12724-12733. CrossRef Medline

Zhu Z, Zheng T, Lee CG, Homer RJ, Elias JA (2002) Tetracycline-controlled transcriptional regulation systems: advances and application in transgenic animal modeling. Semin Cell Dev Biol 13:121-128. CrossRef Medline

Zhuo L, Theis M, Alvarez-Maya I, Brenner M, Willecke K, Messing A (2001) hGFAP-cre transgenic mice for manipulation of glial and neuronal function in vivo. Genesis 31:85-94. CrossRef Medline 